No. 4094 April 17, 1948

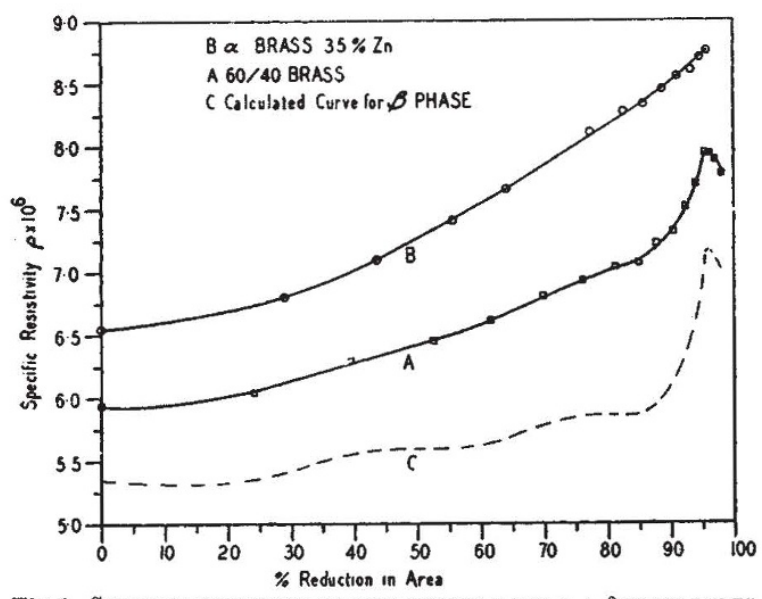

Fig. 1. SPECIFIC RESISTIVITY OF COLD-DRAWN $\alpha$ AND $\alpha+\beta$ BRASS WIRES

In Fig. 1 (curve $A$ ) the electrical resistivity is plotted against the degree of deformation. The resistivity increases with deformation, at first almost linearly, but more rapidly at higher deformations. After 95 per cent reduction in area, the specific resistivity had increased by about 33 per cent. At still higher deformations the resistivity slightly decreased.

To determine the individual behaviour of the $\alpha$ and $\beta$-phases in the duplex wire, a similar series of measurements was made on a single-phase brass wire containing $35 \cdot 1$ per cent zine, which is approximately the zinc content of the $\alpha$-phase in the duplex brass. The results are shown in Fig. 1 (curve $B$ ). Although the resistivity of the $\alpha$-brass also increases markedly with deformation, there is no rapid increase after heavy deformations. Assuming that the duplex alloy consists of equal parts by volume of each phase and that the $\alpha$-phase in it behaves in the same way as the $\alpha$-phase wire, then the behaviour of a wire consisting entirely of the $\beta$-phase can be deduced (Fig. 1, curve $C$ ). This curve indicates that the resistivity of the $\beta$-phase changes little up to 85 per cent reduction in area, where the curve turns steeply upwards. After 95 per cent reduction in area, the curve begins to fall.

In order to ascertain that this increase at high deformations was not a result of cracking, the wires were annealed in hydrogen at $800^{\circ} \mathrm{C}$. for 30 minutes and furmace-cooled, that is, they received the same treatment as before deformation. Thus no difference

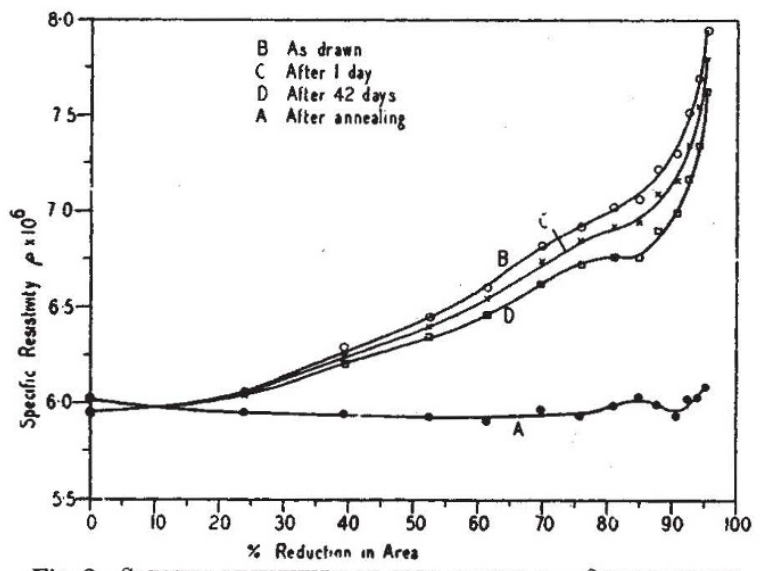

Fig. 2. SPECIFIC RESISTIVITY OF COLD-DRAWN $\alpha-\beta$ BRASS WIRES in the distribution of the two phases should have occurred. The results of resistivity measurements on the annealed wires are shown in Fig. 2 (curve $A$ ), which indicates that all the wires have specific resistivities close to that of the original wire prior to drawing. Moreover, microscopic investigation showed no evidence of cracking, and the mere fact that the wires can be drawn still further points in the same direction. Thus the steep increase in resistivity of the duplex wires after heavy deformations can only be attributed to the disordering of the $\beta$-phase. After 95 per cent reduction the $\beta$-phase has apparently become completely disordered when further cold work has little effect on the resistivity. That this occurs only after an unusually high extent of total deformation is probably due to the fact that in the duplex alloy the $\beta$-phase receives a smaller fraction of the deformation than the ductile $\alpha$-phase.

The resistivity of the duplex wire decreased with time after drawing. Fig. 2 shows the resistivity on drawing $(B$, corresponding to Fig. $1 A$ ) after one day $(C)$ and after forty-two days $(D)$. It will be seen that after forty-two days the increase in resistivity produced by intensive cold work has decreased by 20 per cent. Further experiments showed that this recovery was in fact complete after twenty-seven days, and a subsequent decrease in resistivity after a period of seventy-nine days was only just measurable. In contrast with these results on duplex wires, $\alpha$-phase wires showed no pronounced recovery, any decreases being of the order of $\frac{1}{2}$ per cent six days after drawing. It is thus concluded that the $\beta$-phase is responsible for the changes in resistivity with time of the drawn duplex brass wires. The disordered state produced in the $\beta$-brass is presumably not completely stable, and a certain degree of re-ordering occurs at room temperature.

The marked change in resistivity produced by working a single-phase brass wire ( 35 per cent zinc) is also interesting. We found that the resistivity of brass wires of other compositions also increased, although that of pure copper did not. This fact is in contrast to statements made in the literature ${ }^{4}$ that the electrical resistivities of terminal solid solutions are not affected by cold work. It does not seem improbable that a certain degree of order exists in $\alpha$-brass and even in other $\alpha$-solid solutions.

The work described above was carried out as part of the programme of the Section of Tribophysics, of the Council for Scientific and Industrial Research, Australia.

${ }^{2}$ Smith, C. S., Trans. Amer. Inst. Min. Met. Eng., 152, 144 (1943) ' Honeycombe, R. W. K., and Boas, W., Nature, 159, 847 (1947).

Dahl, o., Z. Metallk., 28, 133 (1936).

'For example, Nix, F. C., and Shockley, W., Rev. Mod. Phys., 10, 57 (1938).

\section{ROOFS SUPPORTED BY AIR PRESSURE}

\section{BY HERBERT H. STEVENS, JUN. 1270 Sixth Avenue, New York 20}

$\mathrm{R}^{\mathrm{o}}$ OOFS supported by air pressure are being seriously considered for long-span building construction as the result of tests conducted at New York University for the United States War Production Board in 1944 .

Flat, circular membranes, fixed around the periphery, were stretched above the elastic limit by air 
pressure to shallow dome shape, and were tested for load-bearing properties and stability at slight, continuously maintained pressures. Neither unsymmetrical loading on sheet steel models up to $12 \mathrm{ft}$. in diameter nor wind-tunnel tests disclosed undesirable features.

Besides theoretical studies of stress and strain distribution in the membrane, construction features and experience obtained with actual pressuresupported roofs were investigated. One of these structures was a semi-cylindrical roof, $25 \mathrm{ft}$. radius, $200 \mathrm{ft}$. long, built of 22-gauge sheet steel on formwork which was supplanted by $0.5 \mathrm{lb}$. per sq. in. air pressure after the ends were closed with a flexible connexion and the floor rendered airtight. This structure was built in 1934 at Minneapolis and was used as a 70,000-bushel grain bin for a year, after which it was dismantled because grain dust in suspension constituted an explosion hazard. Another structure investigated was a series of flexible-roofed inflated gas holders built of thin steel plates up to $300 \mathrm{ft}$. in diameter.

Because air-supported roofs offer enormous spans with the minimum of structural materials, they have caused considerable interest. The aeroplane manufacturer, Glenn L. Martin, proposed an 800-ft. diameter roof for a football stadium at Baltimore in 1945, shortly before the construction of amusement structures was forbidden by the U.S. Government. This roof was to have been of 52-SO aluminium alloy $0 \cdot 109 \mathrm{in}$. thick with welded seams, and was to be supported by $0.06 \mathrm{lb}$. per sq. in. (gauge) air pressure maintained by ordinary ventilating fans discharging into the enclosure formed by the walls and ground. Entrance and exit were to be by revolving doors, and means were included for raising the pressure to balance snow loads and to supply power in case of power failure. The roof membrane was to be anchored to a concrete compression ring around the periphery of the stadium having sufficient strength to withstand the inward pull of the membrane to its yield strength. The membrane was to be formed by air pressure to finished shape from a somewhat flatter constructed shape. This would relieve stresses in the welded seams and tight spots in the membrane, and constitute a proof test of the structure. The air pressure to do this was calculated to be about $0 \cdot 22 \mathrm{lb}$. per sq. in., a pressure of small physiological importance, and one obtainable with the ventilating blowers. This pressure would be about that needed to support $2.5 \mathrm{ft}$. of snow; and the roof capable of containing this pressure would also be capable of withstanding the lifting effect of a wind velocity of 125 miles an hour. These figures were based on the experiments previously mentioned. It was also found with a flutter model in the wind tunnel that a slight excess pressure maintained in the structure prevents rippling or flutter of the roof.

A number of other buildings using this roof have been considered, although none, so far, has been built. These include smaller structures about $300 \mathrm{ft}$. in diameter in which the circular anchor ring is carried overhead on columns and the building space extended underneath to fill out the corners of the lot. Structures ranging upwards to $1,800 \mathrm{ft}$. in diameter for industrial buildings, storage warehouses, commercial and amusement structures where clear span and low cost were important factors have been investigated. It was discovered that such structures could probably be built over the poorest of soils, since the roof loads were evenly transmitted to the floor and not concentrated at the footings. Another factor of interest is that positive pressure within the structure precludes outside air leakage into the building, making exceptional control of the interior atmosphere possible.

A weatherproof transparent plastic of possible use for these roofs is being developed in the United States. If the material, now in pilot-plant construction, is satisfactory, the utility of these roofs would be enormously extended. An unofficial group in Washington, D.C., is investigating the use of a transparent roof over a central courtyard surrounded by a block of apartments for human habitation, and following a suggestion of Prof. J. D. Bernal, a group in Salt Lake City, Utah, is investigating its possibilities for the growing of plants in waterless areas where the moisture may be conserved by the roof. The possibilities of extending the food-growing areas of the world by a technique involving little more than the cost of the plastic and the anchoring means might be of great importance. Likewise the possibility of inexpensively separating large areas from the prevailing atmosphere, and rendering them climatically inhabitable, may have considerable effect in the tropics.

A British Patent 591985 has been allowed on this construction and is endorsed Licence of Right.

\section{PRODUCTION OF AN ANTIBIOTIC SUBSTANCE ON WHEAT STRAW AND OTHER ORGANIC MATERIALS AND IN THE SOIL}

\author{
BY ERNA GROSSBARD \\ Experimental and Research Station, Cheshunt
}

$\mathrm{M}$

ANY soil micro-organisms produce under artificial conditions antibiotic substances which inhibit the growth of certain plant pathogens. On the assumption that a similar process may take place in the soil, investigations on this problem were com menced at the Research Station, Cheshunt, and an attempt made to devise a method whereby antibiotic substances will be produced abundantly in the soil for the purpose of controlling soil-borne diseases. Blair ${ }^{1}$, Garrett ${ }^{2}$, Millard and Taylor ${ }^{3}$, West and Hildebrand 4 , Sanford ${ }^{5}$, and others, have reported that organic manuring reduced the incidence of certain soil-borne diseases and have suggested that microbial antagonism may be one of the important factors.

Our experiments here have shown that certain micro-organisms known to produce antibiotic substances on synthetic media, such as Aspergillus clavatus, Aspergillus terreus, Penicillium patulum and Streptomyces antibioticus, will do so when grown on autoclaved wheat straw to which water has been added ${ }^{6}$.

Penicillium patulum has been studied in detail, because patulin (clavacin), the antibiotic substance produced by it, has a considerable inhibitory effect on the growth of certain plant pathogens ${ }^{6,7,8,8}$. The organism grew well on sterilized soil, but aqueous soil extracts did not inhibit the growth of the test organisms Bacterium coli, Bacillus mycoides and Bacterium phytophthorum. An antibiotic substance was formed, however, when the fungus was grown on sterilized wheat straw, bracken and sugar beet 